\title{
Smoking Prevalence and Its Effect on Dental Health Attitudes and Behavior among Dental Students
}

\author{
Qasem Alomari $^{a}$ Kefah Barrieshi-Nusair $^{a}$ Khalid Said $^{b}$ \\ ${ }^{a}$ Department of Restorative Sciences, Kuwait University, Kuwait; ${ }^{b}$ Department of Preventive Dentistry, \\ Jordan University of Science and Technology, Irbid, Jordan
}

\section{Key Words}

Smoking prevalence $\cdot$ Dental health attitudes $\cdot$ Dental health behavior. Dental students

\begin{abstract}
Objective: To determine smoking prevalence and its effect on dental health attitudes and behavior among dental students in Jordan. Subjects and Methods: A crosssectional study of 314 dental students was conducted at Jordan University of Science and Technology. Subjects were surveyed using a modified version of the Hiroshima University Dental Behavior Inventory (HU-DBI) questionnaire. Multivariate logistic regression analyses were performed to study differences between male smokers and nonsmokers only. Results: The response rate was $83.7 \%$, with $48 \%$ males and $52 \%$ females. The prevalence of smoking was $17.2 \%$. Smoking was more prevalent among male students (31\%) than female (4.3\%). For male students, the multivariate logistic regression analysis showed 6 items that were different between smokers and nonsmokers. Nonsmokers tended to brush their teeth more often than smokers (OR 8.67, 95\% Cl 1.6645.25); claimed that they had never been professionally taught how to brush their teeth (OR 11.15, 95\% Cl 1.8965.67); believed that they spend too much time brushing their teeth (OR 12.24, 95\% Cl 2.0-75.05); were more concerned about having bad breath (OR 41.86, 95\% Cl 3.4458.75) and were more concerned about the color of their
\end{abstract}

gums (OR 8.04, 95\% Cl 1.55-41.84). Conclusions: Smoking prevalence among male dental students in Jordan was high, 7 times greater than for females. Male smokers and nonsmokers had different attitudes and oral health behaviors as indicated by the study survey.

Copyright (C) 2006 S. Karger AG, Basel

\section{Introduction}

Tobacco use is the most preventable cause of death and disability in modern societies. Worldwide, there are 4 million tobacco-related deaths annually, and 30\% of all cancer is linked to tobacco use $[1,2]$. Available evidence suggests that the risk of disease increases with greater use of tobacco whereas quitting smoking can result in decreasing that risk [3]. Tobacco is also a significant risk factor for oral diseases such as periodontal disease, ulcers, cleft lip and palate, and coronal and root caries. Wound healing, dental implants, cosmetic treatments and cancer therapy all are compromised by patients' tobacco consumption $[4,5]$. Cigarette smoking was found to be negatively associated with oral health status (periodontal disease, missing teeth, and decayed teeth) regardless of the dental health behavior of the patient [6]. Moreover, research showed that tobacco users brushed and flossed their teeth less frequently and had more oral health problems than the nonusers [7].

\section{KARGER}

Fax +4161306 1234 E-Mail karger@karger.ch www.karger.com
(C) $2006 \mathrm{~S}$. Karger AG, Basel

$1011-7571 / 06 / 0153-0195 \$ 23.50 / 0$

Accessible online at:

www.karger.com/mpp
Dr. Qasem D. Alomari

Department of Restorative Sciences, Faculty of Dentistry

Kuwait University, PO Box 24923

13110 Safat (Kuwait)

Tel. +965266 4517, +965 261 1097, Fax +965 263 4247, E-Mail qalomari@hsc.edu.kw 
Signs of smoking such as odor, tooth stain, poor oral hygiene, and the aforementioned oral diseases make tobacco use very obvious to dentists. The typical dental appointment is usually long, affording opportunity for dentist-patient discussion of tobacco use and its consequences [8]. In the US, when dentists were asked if they thought that they should encourage their patients to stop smoking, over two thirds responded in the affirmative [9]. Yet only one third of them believed that they were effective in this area and only about one quarter of current smokers received advice from their dentists to quit using tobacco [10]. Fewer than $10 \%$ of US dentists reported that they had adequate knowledge of smoking cessation techniques $[11,12]$.

Indications from published studies are that health professionals who smoke may not be as effective in counseling patients to quit smoking as health professionals who do not smoke $[13,14]$. The help and advice of health professionals in smoking cessation are very important, yet many oral health professionals continue to smoke. Dentists must set an example as a role model for their patients, families and friends by not smoking.

Despite acquiring an increased knowledge about risk factors and the pathogenesis of tobacco-related diseases during their healthcare professional education, students begin or continue to smoke during their studies at university. The purpose of this study was to examine the prevalence of smoking among dental students in Jordan and document the effects of smoking on students' dental health attitudes and behavior.

\section{Subjects and Methods}

Students from all 5 academic years at Jordan University of Science and Technology were asked to participate in the study. Participation was voluntary and consent was indicated through survey completion.

A modified English version of the Hiroshima University-Dental Behavior Inventory (HU-DBI) survey [15] was used in this study. The survey was type-written in English and distributed to dental students at the end of classes. Questions from the students regarding the meaning of the words were allowed and answers to such questions were announced to the other students. The survey was based on 17 items (table 1). It was completed anonymously and no information about the academic record of the student was collected. Students had to specify their gender, academic year, whether or not they were smokers and how much and for how long they had been smoking.

There was no common background between the students regarding place of birth, living area or socioeconomic status. This research was approved by Deanship of Research as well as the Deanship of Human Rights Committee.
Table 1. The modified HU-DBI survey used in this study

\begin{aligned} & \hline No. Item description \\ & \hline 1 I live with my family now \\ & 2 I have been to a dentist office before \\ & 3 I do not go to the dentist unless I have a toothache \\ & 4 I brush my teeth twice daily or more \\ & 5 My gums bleed when I brush my teeth \\ & 6 I have never been professionally taught how to brush \\ & 7 I think my teeth are getting worse despite my daily brushing \\ & 8 I don't feel I have brushed my teeth properly unless I brush \\ & with strong strokes \\ & 9 I feel that I spend too much time brushing my teeth \\ & 10 I think I can clean my teeth without using toothpaste \\ & 11 It is impossible to prevent gum disease with toothbrushing \\ & alone \\ & 12 I use tooth floss on regular basis \\ & 13 I use mouthwash on regular basis \\ & 14 I worry about having bad breath \\ & 15 I am bothered by the color of my gums \\ & 16 I worry about the color of my teeth \\ & 17 I am satisfied with the appearance of my teeth \\ & \hline\end{aligned}

The response options were no/yes.

Logistic regression analyses were done according to Hosmer and Lemeshow [16]. Univariate analyses comparing answers given by smokers and nonsmokers, respectively, were done first. Next, a stepwise backward selection strategy was employed to construct multivariate logistic regression models with nonsmoking status as dependent variable. Any question with a $p$ value of $<0.05$ was allowed to enter the model and was omitted from the model at $\mathrm{p} \geq$ 0.05 . Finally, trends of change in answering certain questions were analyzed. Since most of the smokers were males, the multivariate logistic regression models were repeated for males only with the same selection criteria for inclusion and exclusion. The odds ratios $(\mathrm{OR})$ and $95 \%$ confidence intervals $(\mathrm{CI})$ were calculated. Systat ${ }^{\circledR}$ 8.0 (SPSS Inc., Chicago, USA) statistical program was used to process the data and for statistical analysis.

\section{Results}

Of a total of 375 dental students, 314 (83.7\%) completed the questionnaire. The distribution of the participating students by academic year and gender is presented in table 2. The participation rate was not different between the academic years, ranging from 81 to $88 \%$.

As shown in table 3, the percentage of male student smokers was $31 \%$ while it was only $4.3 \%$ for females. Of the smokers, only $11.4 \%$ smoke 10 cigarettes or more per day. About $15 \%$ have been smoking for more than a year from the date of the questionnaire. 
Table 2. Distribution of the participating dental students by academic year and gender

\begin{tabular}{llll}
\hline Academic year & Number $(\%)$ & \multicolumn{2}{l}{ Gender } \\
\cline { 3 - 4 } & & male (\%) & female (\%) \\
\hline 1st & $98(81)$ & $42(43)$ & $56(57)$ \\
2nd & $70(87.5)$ & $40(57)$ & $30(43)$ \\
3rd & $51(81)$ & $27(53)$ & $24(47)$ \\
th & $39(85)$ & $14(36)$ & $25(64)$ \\
5th & $56(87.5)$ & $28(50)$ & $28(50)$ \\
\hline Total & $314(83.7)$ & $151(48)$ & $163(52)$ \\
\hline
\end{tabular}

Table 3. Distribution (\%) of smokers, male smokers, who smoke $\geq 10$ cigarettes a day, and who have been smoking for $\geq$ a year among different academic years

\begin{tabular}{lclll}
\hline $\begin{array}{l}\text { Academic } \\
\text { year }\end{array}$ & Smokers & $\begin{array}{l}\text { Male } \\
\text { smokers }\end{array}$ & $\begin{array}{l}\geq 10 \text { cigarettes } \\
\text { per day }\end{array}$ & $\begin{array}{l}\text { Smoking } \\
\text { for } \geq \text { a year }\end{array}$ \\
\hline 1st & 33.3 & 83.3 & 21.4 & 21.4 \\
2nd & 31.5 & 94.1 & 22.9 & 21.4 \\
3rd & 7.4 & 75.0 & 7.8 & 7.8 \\
4th & 3.7 & 50.0 & 5.1 & 5.1 \\
5th & 24.1 & 92.3 & 23.2 & 23.2 \\
\hline Total & 17.2 & 87.0 & 11.4 & 14.9 \\
\hline
\end{tabular}

Table 4. Results of multiple logistic regression analysis for males only

\begin{tabular}{|c|c|c|c|c|c|c|}
\hline & Constant & -13.839 & 4.971 & 0.005 & & \\
\hline 4 & I brush my teeth twice daily or more & 2.159 & 0.843 & $0.010^{*}$ & 8.67 & $1.66-45.25$ \\
\hline 6 & I have never been professionally taught how to brush & 2.411 & 0.905 & $0.008 *$ & 11.15 & $1.89-65.67$ \\
\hline 9 & I feel that I spend too much time brushing my teeth & 2.505 & 0.925 & $0.007 *$ & 12.24 & $2.00-75.05$ \\
\hline 14 & I worry about having bad breath & 3.734 & 1.274 & $0.003^{*}$ & 41.86 & $3.44-58.75$ \\
\hline
\end{tabular}

Dependent variable: smoking status. Response: nonsmokers. Likelihood ratio 93, 8 d.f., p $<0.000$. Numbers of questions not included in the model: $1,2,3,5,7,8,10,11,12,13,16$.

* Statistically significant.

The multivariate logistic regression analysis model for male students is given in table 4; 6 answers differ significantly $(p<0.05)$ between smokers and nonsmokers. Nonsmokers brushed their teeth more often (item 4) (OR 8.67, CI 1.66-45.25) than smokers. Also the number of students who had never been professionally taught how to brush their teeth (item 6) was significantly higher among nonsmokers (OR 11.15, CI 1.89-65.67). More than smokers, nonsmokers feel that they spend too much time brushing their teeth (item 9) (OR 12.24, CI 2.075.05).

Nonsmokers were more concerned about having bad breath (item 14) (OR 41.86, CI 3.44-58.75) and were more concerned with the color of their gums (item 15) (OR 8.04, CI 1.55-41.84). Finally, nonsmokers were less satisfied with the appearance of their teeth than smokers (OR 0.197, CI 0.04-0.96).

The other items that included living with family, having been to the dentist's office before, consulting a dentist without having a toothache, experiencing bleeding of gums upon brushing, brushing with strong strokes, using toothpaste, dental floss, and/or mouthwash, and being concerned about tooth color were not significantly different between smokers and nonsmokers ( $p \geq 0.05$ ).

\section{Discussion}

This study used the general approach in attitudes/behavior measurements to compare dental student smokers' and nonsmokers' dental health attitudes and behavior. All items of the survey had a dichotomous response format (yes/no). This questionnaire was recently used to compare oral health attitudes and behaviors among dental and dental hygiene students throughout the world [1720]. In a sample of Japanese university students, the HUDBI had good test-retest reliability over a 4-week period [21]. The English version has also shown good test-retest 
reliability and translation validity in a sample of 26 bilingual individuals [22]. Translation of HU-DBI survey from English to Arabic was not needed as students started their English early in elementary school and because English is the language of instruction at the dental school. Translation might indirectly influence the results, which would prevent comparing our study to other studies. The questionnaire was modified to be more suitable to our students and culture.

Participation in the survey was voluntary. While some of the students were absent on the day of the survey distribution, very few chose not to participate. The participation rate $(83.7 \%)$ was considered good for the purpose of the survey.

Haddad and Malak [23] reported that the prevalence of smoking among the general student population at Jordan University of Science and Technology was approximately $30 ; 50$ and $7 \%$ for males and females, respectively. Our study showed that the prevalence of smoking among dental students was lower than that among other students at Jordan University of Science and Technology. This may be due to the fact that dental students are expected to be more knowledgeable about the health risk associated with tobacco use.

A study by Burgan [24] in 2003 found that 35\% of Jordanian dentists were tobacco users; $83 \%$ were daily smokers and about $20 \%$ smoked 20 or more cigarettes per day. Two thirds were men younger than 40 years of age who worked in private practice. In comparison to our study, it is clear that smoking is less prevalent among dental students than dentists. It is probable that dentists have more expendable income.

The prevalence of smoking among Jordanian dental students was much higher than that in the region [25] and in developed countries [26]. The probable explanation for the high rate of smoking among our students may be due to cultural behavior and people's perception of smokers in society. Considerable effort needs to be made towards changing our dental students' smoking habit so that they become role models for their society.

Despite the fact that the students acquire knowledge about tobacco-related diseases, they continue to smoke during their studies at the university. Research showed smoking to be more frequent among male students compared to female students [27] and to rise progressively with age and level of education [28]. This is in agreement with the results of our study, as smoking was more prevalent among male students than females. It was obvious that prevalence of smoking decreased with progression of the students in their academic studies: $33.3 \%$ first-year students compared to $3.7 \%$ in the fourth year. However, smoking prevalence increased again among the final-year students. The reason for this is difficult to explain, but one might suggest it is due to the different kinds of stress and tension that the students are exposed to during their final year at the university.

In general, the results of previous studies [29] showed that nonsmokers have more healthy dental behaviors than smokers. According to our results, except for the frequency of toothbrushing, there was no difference between smokers and nonsmokers in their dental health behavior. There was no difference in flossing or using mouthwash between the two groups. On the other hand, smokers showed worse dental health attitudes. They were less concerned about the health of their gums and the color of their teeth than nonsmokers. Also, they were not worried about having bad breath.

Reviewing the dental school's curriculum showed that smoking education was part of a preventive dentistry course which is taught to the students at the third year. We strongly recommend that the curriculum involve theoretical and practical education about risks of smoking for oral health throughout the 5 years of dental education. Obligatory workshops should be held for all students to learn about smoking and smoking cessation within the framework of preventive courses. In addition, selected students should be encouraged to undertake studies on smoking and oral health as part of their research. Students can also practice their skills on tobacco counseling on each other. A class summarizing the topic of smoking and oral health could be added to the final-year curriculum.

\section{Conclusions}

The results of this study showed that the prevalence of smoking among male dental students is high. It also showed that cigarette smoking had a negative effect on the students' dental health attitudes and behaviors. These results underscore the need for greater efforts aimed at tobacco cessation and education of dental students so that they can play an effective role in assessing their patients' tobacco use habits and encourage cessation. In addition, courses other than stress prevention should be included in the curriculum. 


\section{References}

1 Wald NJ, Hackshaw AK: Cigarette smoking: an epidemiological overview. Br Med Bull 1996;52:3-11.

$>2$ Banoczy J, Squier C: Smoking and disease. Eur J Dent Educ 2004;8:7-10.

-3 Johnson GK, Slach NA: Impact of tobacco use on periodontal status. J Dent Educ 2001;65: 313-321.

4 Winn DM: Tobacco use and oral disease. J Dent Educ 2001;65:306-312.

$>5$ Al-Wahadni A, Linden GJ: The effects of cigarette smoking on the periodontal condition of young Jordanian adults. J Clin Periodontol 2003;30:132-137.

-6 Ide R, Mizoue T, Ueno K, Fujino Y, Yoshimura $\mathrm{T}$ : Relationship between cigarette smoking and oral health status (abstract). Sangyo Eiseigaku Zasshi 2002;44:6-11.

7 Andrews JA, Severson HH, Lichtenstein E, Gordon JS: Relationship between tobacco use and self-reported oral hygiene habits. J Am Dent Assoc 1998;129:313-320.

$>8$ Hendricson WD, Cohen PA: Oral health care in the 21st century: implications for dental and medical education. Acad Med 2001;76:11811206.

$\checkmark 9$ Allard RH: Tobacco and oral health: attitudes and opinions of European dentists. A report of the EU working group on tobacco and oral health. Int Dent J 2000;50:99-102.

10 Tomar SL, Husten CG, Manley MW: Do dentists and physicians advise tobacco users to quit? J Am Dent Assoc 1996;127:259-265.

11 John JH, Thomas D, Richards D: Smoking cessation interventions in the Oxford region: changes in dentists' attitudes and reported practices 1996-2001. Br Dent J 2003;195: 270-275.
12 Dolan TA, McGorray SP, Grinstead-Skigen CL, Mecklenburg R: Tobacco control activities in U.S. dental practices. J Am Dent Assoc 1997;128:1669-1679.

13 Olive KE, Ballard JA: Attitudes of patients toward smoking by health professionals. Public Health Rep 1992;107:335-339.

14 Puska PM, Barrueco M, Roussos C, Hider A, Hogue S: The participation of health professionals in a smoking-cessation programme positively influences the smoking cessation advice given to patients. Int J Clin Pract 2005;59: 447-452.

15 Kawamura M, Ikeda-Nakaoka Y, Sasahara H: An assessment of oral self-care level among Japanese dental students and general nursing students using the Hiroshima University-dental behavioral inventory (HU-DBI): surveys in 1990/1999. Eur J Dent Educ 2000;4:82-88.

16 Hosmer DW, Lemeshow S: Applied Logistic Regression, ed 1. New York, Wiley \& Sons, 1989, p 82.

17 Kawamura M: Dental behavioral science: the relationship between perceptions of oral health and oral status in adults. J Hiroshima Univ Dent Soc 1988;20:273-286.

18 Kawamura M, Honkala E, Widström E, Komabayashi T: Cross-cultural differences of selfreported oral health behavior in Japanese and Finnish dental students. Int Dent J 2000;50: 46-50.

19 Kawamura M, Iwamoto Y, Wright FA: A comparison of self-reported dental health attitudes and behavior between selected Japanese and Australian students. J Dent Educ 1997;61: 354-360.
20 Kawamura M, Spadafora A, Kim KJ, Komabayashi T: Comparison of United States and Korean dental hygiene students using the Hiroshima University-dental behavioral inventory (HU-DBI). Int Dent J 2002;52:156-162.

21 Kawabata K, Kawamura M, Miyagi M, Iwamoto Y: The dental health behavior of university students and test-retest reliability of the HU-DBI. J Dent Health 1990;40:474-475.

22 Kawamura M, Kawabata K, Sasahara H, Miyagi M: Dental behavioral science. Part IX: Bilinguals' responses to the dental behavioral inventory (HU-DBI) written in English and in Japanese. J Hiroshima Univ Dent Soc 1992; 22:198-204.

23 Haddad LG, Malak MZ: Smoking habits and attitudes towards smoking among university students in Jordan. Int J Nurs Stud 2002;39: 793-802.

24 Burgan SZ: Smoking behavior and views of Jordanian dentists: a pilot survey. Oral Surg Oral Med Oral Pathol 2003;95:163-168.

25 Almas K, Al-Hawish A, Al-Khamis W: Oral hygiene practices, smoking habit, and self-perceived oral malodor among dental students. J Contemp Dent Pract 2003; 15:77-90.

26 Najem GR, Passannante MR, Foster JD: Health risk factors and health promoting behavior of medical, dental and nursing students. J Clin Epidemiol 1995;48:841-849.

27 Maziak W, Mzayek F: Characterization of the smoking habit among high school students in Syria. Eur J Epidemiol 2000;16:1169-1176.

28 Johnson NW: The role of the dental team in tobacco cessation. J Dent Educ 2004; 8:1824.

29 Jones RB: Tobacco or oral health: past progress, impending challenge. J Am Dent Assoc 2000;131:1130-1136. 